\section{Rapunzel syndrome: how to orient the diagnosis}

Enrico Finale, 1,2

Piergiorgio Franceschini, ${ }^{3}$

Cesare Danesino, 4

Michelangelo Barbaglia, ${ }^{1}$

Andrea Guala1

1Maternal-Child Department, ASL

Verbano-Cusio-Ossola; ${ }^{2}$ Pediatrics

Department, Castelli Hospital,

Verbania; ${ }^{3}$ University of Turin;

${ }^{4}$ Department of Molecular Medicine,

University of Pavia, Italy

\begin{abstract}
Rapunzel syndrome is a rare form of tricobezoar with a tail extending from the stomach into the small bowel; surgical removal is generally required. About 60 cases have been reported and described in the literature since 1968 . We present the case of an 8-year-old girl who, during the course of a genetic consultation, was initially assigned with a clinical suspicion of ectodermal dysplasia. Surgical intervention, which resulted in the extraction of a tricobezoar of enormous size and extension, led us to the diagnosis of Rapunzel syndrome. The possibility of a tricobezoar should be considered in all cases of adolescent patients who present signs of intestinal occlusion or sub-occlusion, suffer from psychiatric disorders, and have a history of trichotillomania. Endoscopic methodology, medical imaging and clinical diagnostics are fundamental for a differential diagnosis. Psychiatric follow-up is advised to prevent recurrence.
\end{abstract}

\section{Introduction}

Rapunzel syndrome was described for the first time in 1968 by Vaughan et al.,1 and the name comes from the famous Grimm Brothers' fairy tale of a young 12year-old girl, locked up in an inaccessible tower, and the young prince who climbs up her long tresses in an attempt to save her. ${ }^{2}$

Rapunzel syndrome is a rare condition that results following the formation of an occluding tricobezoar in the gastrointestinal tract.

Symptoms are often not clearly identified with the syndrome. The following however, seem to be transversal and connected to the presence of a tricobezoar: nausea and vomiting, epigastric/adominal pain, weight loss and anorexia, intestinal occlusion and sub-occlusion $^{3}$ and even death, in rare cases. ${ }^{4,5}$ What is common to all cases is a history of trichotillomania and trichophagia in the patient, a condition which predisposes the formation of the tricobezoar.

\section{Case Report}

We present the case of a young girl with a clinical suspicion of ectodermal dysplasia indicated during the course of a genetic examination for patchy hair and nail bed dysplasia. The physical examination revealed dry thinning hair (Figures 1 and 2), short, dysplastic and slow-growing fingernails, and decidual dentition, except for the medial upper incisors. The child had also always been on the lower end ( $10^{\text {th }}$ centile) of the growth curve, both underweight, as well as in height. Notwithstanding the diagnostic suspicion, some of the expected abnormalities were not present, such as the inability to perspire, which however is not always altered, especially in females. In fact, the most frequent form of ectodermal dysplasia is X-linked (about $80 \%$ of cases), thus females are healthy carriers, or in rare cases, manifest variable symptoms of the syndrome. The patient did not present acute symptomatology and during the clinical examination showed no obvious signs of serious psychiatric pathologies, or evident anxiety, depression or mood swings. A few days after the genetic consultation, the patient was admitted to the hospital with acute epigastric pain, nausea and vomiting. Abdominal palpation detected a non-tender, compact and painful abdominal mass in the epigastrium which was confirmed by an ultrasound scan. Taken urgently into the operating theatre, the patient underwent a mini-laparotomy. When called into the operating room by the surgeons, we were shown an enormous tricobezoar weighing $1 \mathrm{~kg}$ and measuring $38 \times 12,5$ (Figure 3 ). The patient was referred to a child psychiatrist.

\section{Discussion}

The formation of a bezoar is a very rare event, in fact it is estimated that development occurs in only $1 \%$ of those patients suffering from trichophagia.6,7 The formation of a tricobezoar is due to the indigestible composition of hair; the slippery strands become entangled in the gastric
Correspondence: Enrico Finale, Pediatrics Department, Castelli Hospital, Verbania, Via Fiume 18, 28922 Verbania, Italy.

Tel.: +39.0323.541333 - Fax: +39.0323.541334.

E-mail: enrico.finale@gmail.com

Key words: Rapunzel syndrome; diagnosis.

Contributions: EF, PF, CD, AG: substantial contributions to the conception and design of the work; acquisition, analysis and interpretation of data; $\mathrm{EF}, \mathrm{MB}, \mathrm{AG}$ : drafting of the manuscript and revising it critically for important intellectual content; EF, PF, MB, CD, AG: final approval of the version to be published; $\mathrm{EF}, \mathrm{PF}, \mathrm{MB}, \mathrm{CD}$, AG: accountable for all aspects of the work and declare that due care, diligence and all other requisite investigations were carried out in the preparation of the research to ensure its accuracy and integrity.

Conflict of interest: the authors declare no potential conflict of interests.

Funding: none.

Received for publication: 23 March 2018.

Accepted for publication: 24 June 2018.

This work is licensed under a Creative Commons Attribution NonCommercial 4.0 License (CC BY-NC 4.0).

(C) Copyright E. Finale et al., 2018

Licensee PAGEPress, Italy

Pediatric Reports 2018; 10:7689

doi:10.4081/pr.2018.7689

folds and, escaping peristaltic propulsion, continue to accumulate into a large mass, which then stimulates bradygastria in the stomach. Three conditions seem to be common to all causes of Rapunzel syndrome: a trichobezoar with tail; extension of the tail at least to jejunum, ileum or colon, and symptoms of obstruction. 3,8 Since publication of the first case in 1968, about 60 cases have been reported in the literature. ${ }^{9}$ It seems that females are more predisposed to developing the pathology. 3,10

Differential diagnosis may prove difficult due to the transversal symptoms which do not often or immediately lead to a diagnosis of Rapunzel syndrome. Furthermore, along with symptoms characteristic of an intestinal sub-occlusion or occlusion, the patient may also present gastric ulcers, intestinal perforation, diarrhea and, in some cases, vitamin B12 deficiency (due to the bacterial colonization of the bezoar). ${ }^{11}$ The gold standard for diagnosis is the use of diagnostic gastrointestinal endoscopy and imaging. ${ }^{11}$ 


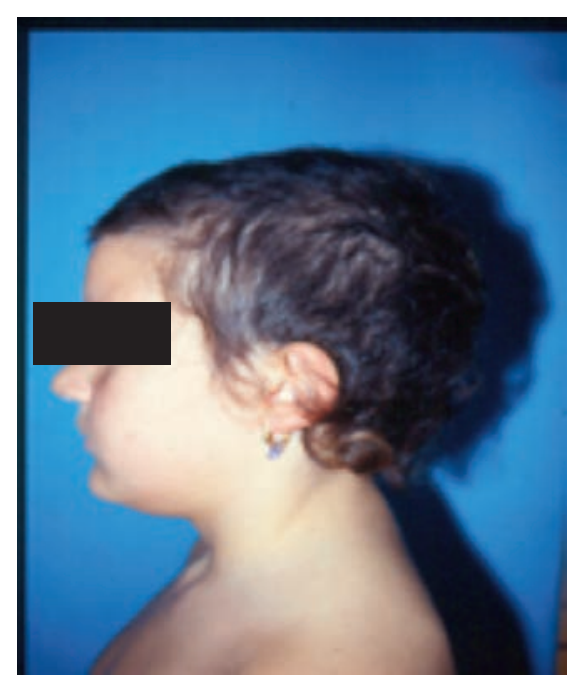

Figure 1. Scalp with inhomogeneous distribution.

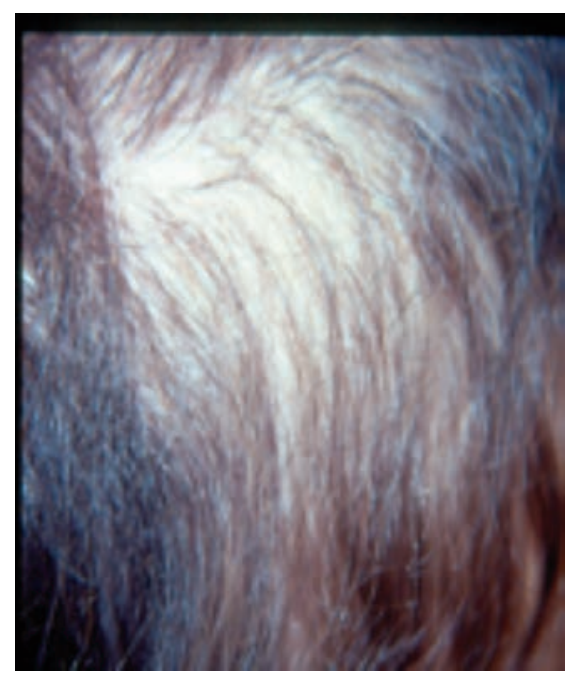

Figure 2. Rare scalp with damaged hair.

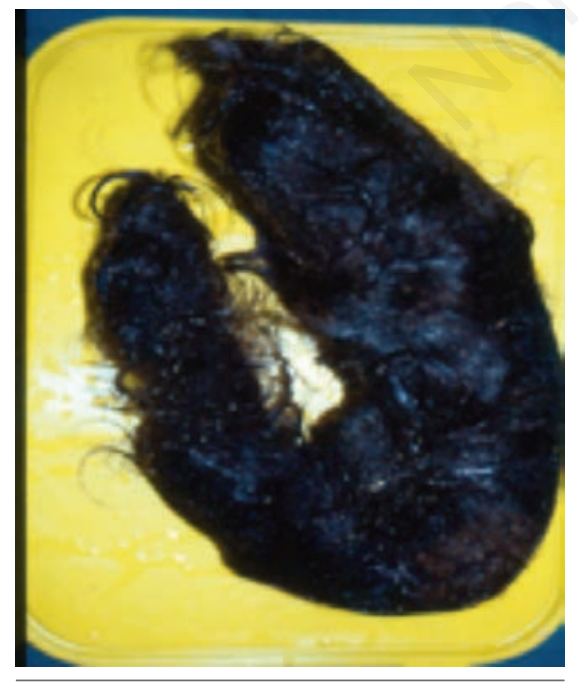

Figure 3. Trichobezoar: $38 \times 12.5$ weighing $1 \mathrm{~kg}$.

\section{Conclusions}

Rapunzel syndrome is extremely rare and difficult to diagnose. It should be suspected in the presence of abdominal pain, vomiting and weight loss especially in adolescents or in young women with a history of psychiatric disorders (primarily trichotillomania and trichofagia). Clinical and endoscopic exams, along with diagnostic imaging, are indispensable instruments for reaching a differential diagnosis and deciding on eventual treatment. Of fundamental importance is psychiatric follow-up to prevent recurrence over time.

\section{References}

1. Vaughan ED, Sawyers JL, Scott HW. The Rapunzel syndrome. An unusual complication of intestinal bezoar. Surgery 1968;63:339-43.

2. Grimm Brothers. Rapunzel. Translated by Godwin-Jones R. Richmond. Virginia Commonwealth University: Department of Foreign Languages; 1994-1999.

3. Naik S, Gupta V, Naik S, et al. Rapunzel syndrome reviewed and redefined. Dig Surg 2007;24:157-61.

4. Koç O, YildIz FD, Narci A, Şen TA. An unusual cause of gastric perforation in childhood: trichobezoar (Rapunzel syndrome). A case report. Eur J Ped 2009;168:495-7.

5. Mohite PN, Gohil AB, Wala HB, Vaza MA. Rapunzel syndrome complicated with gastric perforation diagnosed on operation table. J Gastrointestin Surg 2008;12:2240-2.

6. Phillips MR, Zaheer S, Drugas GT. Gastric trichobezoar: Case report and literature review. Mayo Clin Proc 1998;73:653-6.

7. Irving PM, Kadirkamanathan SS, Priston AV, Blanshard C. Education and imaging. Gastrointestinal: Rapunzel syndrome. J Gastroenterol Hepatol 2007;22:2361.

8. Chauhan NS, Kumar S, Bhoil R. Rapunzel Syndrome: Rare "tale" of a broken "tail". Pol J Radiol 2016;81: 166-9.

9. Kim SC, Kim SH, Kim SJ. A case report: large trichobezoar causing Rapunzel Syndrome. Medicine 2016;95:e3745.

10. Sharma AK, Hussain A, Walia D, Bansal S. Trichobezoar and Rapunzel syndrome: A review. Oncol Gastroenterol Hepatol Rep 2015;4:289.

11. Altonbary AY, Bahgat MH. Rapunzel syndrome. J Transl Int Med 2015;3:7981. 